\title{
Rapid Prototyping of Engineered Heart Tissues through Miniaturization and Phenotype-Automation
}

\author{
Tetsuro Wakatsuki \\ Department of Physiology, Biotechnology \& Bioengineering Center, \\ Medical College of Wisconsin, Milwaukee, Wisconsin, \\ InvivoSciences, LLC, McFarland Wisconsin,
}

U.S.A.

\section{Introduction}

Organ transplantation is a lifesaving procedure, yet the demand for transplants far exceeds the available supply. Each year, nearly seven thousand patients in the United States die while waiting for an organ transplant [1]. Developing heart muscles in vitro for transplantation [3] [4] is one approach that could ultimately overcome this critical shortage. For complex tissues such as a heart muscle, the final product has to mimic physiological functions as well as the regulatory system for regenerating the recipient's tissue functions. Successful development of implantable and functional engineered tissues is currently hindered by the time-consuming and cost-intensive processes through which developers iteratively work to optimize tissue-fabrication protocols, needing to establish proper culture conditions and the ideal quantities of materials used. To overcome these burdens, it is critical to establish a prototyping process by which the developers can explore many parameters rapidly using minimal resources. To achieve this goal, 1) the prototypes of engineered tissues have to be small enough to save materials, including cells, extracellular matrices and growth factors that are necessary for the in vitro heart tissue development, and 2) the assay system to evaluate the heart tissue function has to be automated for rapid highthroughput analysis of prototyping results. In addition, a stable source of cells must be carefully selected to maintain the reproducibility of tissue production while scaling up the manufacturing capability.

\section{Miniaturizing biological samples and products}

Size of engineered tissue (ET) varies based on research needs. To systematically screen and analyze a large number of parameters that determine tissue function, the size of ETs has to be defined based on the required throughputs and phenotying assays for the tissue function analysis. Fully-grown cardiac muscle cells in three dimensional matrices are at least $100 \mathrm{um}$ in length along their longitudinal axis [5]. Therefore, engineered heart tissues (EHTs) should be at least several times larger than the size of single cells in order to form multi-cellular functional cardiac muscles. In addition, the statistical significance of data improves 
significantly when using multi-cellular tissues rather than single cells [6] because the tissue samples contain from tens of thousands to over a million cells. The functional assay data collected using tissues represents an average function of many cells embedded in the tissues. By applying the photolithographical techniques, smaller, micro-scale (50-200 um) engineered tissues can be fabricated [7] to mimic intricate shapes of native tissues. However, in these micro-scale tissues, it is yet to be determined if there is an improvement of the statistical significance of functional data over that from single cells. At present, ETs in millimeter scale have been used for the functional assays with relatively good data reproducibility [8] [9]. By using ETs, a statistically significant data can be obtained using only 4-8 samples [9] instead of collecting ranging 60-600 data points per well in cell-based assays [10].

Unlike the rapid prototyping of parts with synthetic materials, the prototyping of engineered tissues with live cells has to consider the behavior of tissues after fabrication in a given culture condition. Cells are a vital element of developing functional organs and tissues. While consuming nutrients and receiving extracellular stimuli, the cells synthesize, secrete, and degrade proteins, divide, and remodel tissues. Therefore, developers of engineered tissue have to take these aspects into account for the design and development of engineered tissue samples and products. Behaviors of cells have been studied extensively to understand the molecular mechanisms by which biological functions of cell are regulated [11]. Because the cell behavior should underlie function of tissues and organs, the vast amount of information that has been accumulated through studies of cells should be used to understand tissue and organ function. However, some recent findings indicate that biology of cells cultured in two dimension (2D) is not entirely the same as that of cells cultured in a three dimensional (3D) environment, which is more similar to the in vivo environment in which cells reside.

\section{2D vs 3D cell based analysis}

Even though cells cultured on a 2D surface have been assumed to closely resemble those in tissues and organs, in some aspects they are quite different from those found in vivo. In vivo, most cells are found embedded within a 3D extracellular matrix (ECM), and their shape and cell-ECM adhesion are different from those in 2D culture [12]. In most 2D cell culture, cells are cultured on infinitely stiff solids. However, in 3D culture, the ECM in which native cells reside can be deformed, stiffened, softened, or degraded to change the mechanics of the tissue. Stem cell linage specification has been observed to be directed by matrix stiffness [13], which strongly suggests that mechanical signaling will play a pivotal role in developing physiologically functional and implantable tissues. A difference in mechanical signal transduction between a $2 \mathrm{D}$ and a $3 \mathrm{D}$ environment was also suggested [14]. For instance, fibroblasts cultured in 3D have intrinsically lower expression levels of the small GPTase Rac than those in 2D cultured cells, which switches the migratory pattern of cells from random to persistent [15]. Reduction of the activity of focal adhesion kinase (FAK) and ERK1/2 in 3D culture, as compared to 2D cultures, has also been reported [12]. There is significant concern over the biological differences observed between 2D cell-culture systems, which have been used to study almost all signal transduction pathways to date [16], and the arguably more physiological 3D cell-culture environment. 
When testing mechanical signaling, the tissues are subjected to mechanical deformations including pushing and stretching. An application of cyclic mechanical stretch to cardiac myocytes and fibroblasts up-regulates various signal transduction pathways through Rho/ROCK activation [17, 18]. Activation of extracellular signal-regulated kinases (ERKs) and up-regulation of an immediate early gene family of transcription factors, and c-fos [19] are well-characterized early responses of cells to the stretching. Up-regulated cellular processes including protein synthesis [20] and myofibril organization [21] are also apparent. The Rho/ROCK signaling pathway also regulates a hypertrophic response in cultured cardiac myocytes after application of soluble factors such as endothelin-1 treatment [22]. Therefore, an intricate balance orchestrated by soluble stimuli, mechanical deformation, and extracellular stiffness dictates the tissue development.

The tissue can function normally under homeostasis, at which the mechanical balance between extra- and intra-cellular activities is balanced. The homeostasis can be shifted by aging or other long term processes but is a quasi-steady state that is required for a tissue's physiological function. For example, physiological wound healing restores the homeostasis in the granulation tissue - fibrous connective tissue of healing wounds - by active fibroblasts contracting open wounds, secreting factors and hormones, and degrading ECMs to reconstruct the damaged tissues [23]. Pathological wound healing, such as keloids and scars in skin [24], fails to restore the homeostasis. A schematic description of potential network system is in shown in Figure 1. Intracellular molecular sensors, such as the src family kinase substrate p130Cas [25], detect the stiffness of extracellular environment to initiate its down-stream signaling events including $\mathrm{Ca}^{2+}$ release, kinase activity, and gene regulation. Expressions of various genes are up-regulated through translocation of transcription factors from cytoplasm into nucleus. Furthermore the gene expression can be coupled to cell contraction. For instance, during the formation of actin stress-fibers in contracting fibroblasts, the balance of actin pools is shifted from a high prevalence of the monomer state to increased polymer levels. This balance shift frees up myocardin-related transcription factors (MRTF)-A, which are bound to monomer actins, and the unbound MRTF-As translocate into nucleus to promote gene expression. Therefore, MRTF-A's downstream up-regulation of wound healing gene-family including collagen type I a1 is tightly coupled to the state of actin polymerization (F- and G- actin ratio) in fibroblasts [26].

In parallel with changing the mechanical environment, the soluble factors, such as TGF $\beta_{1}$, binding to their specific receptors initiate the similar downstream signaling events [27, 28]. Depending on the signaling pathways, the initial signal strength can be amplified. One of recent observations indicates that signal strength is amplified in three-tiered kinase module of Raf-MEK(mitogen-activated protein kinase or extracellular signal-regulated kinase kinase)-ERK (extracellular signal-regulated kinase) by increasing concentrations of kinases involving in downstream (e.g., 1:3:6 = raf-1:MEK:ERK) in COS cells [29]. The soluble and mechanical stimuli result in the development of contractility by actin-myosin interactions, which is one of end-points of the signaling pathways. We hypothesize that the activities of actin-myosin interactions is a part of feedback mechanism by which cells sense the strength of mechanical stimuli and stiffness of extracellular space [30]. Integrin-linked kinase and ECM protein, tenascin-C, have been demonstrated to be a part of the mechanical sensory systems in zebrafish heart [31], skeletal muscles [32], and fibroblasts [33]. 


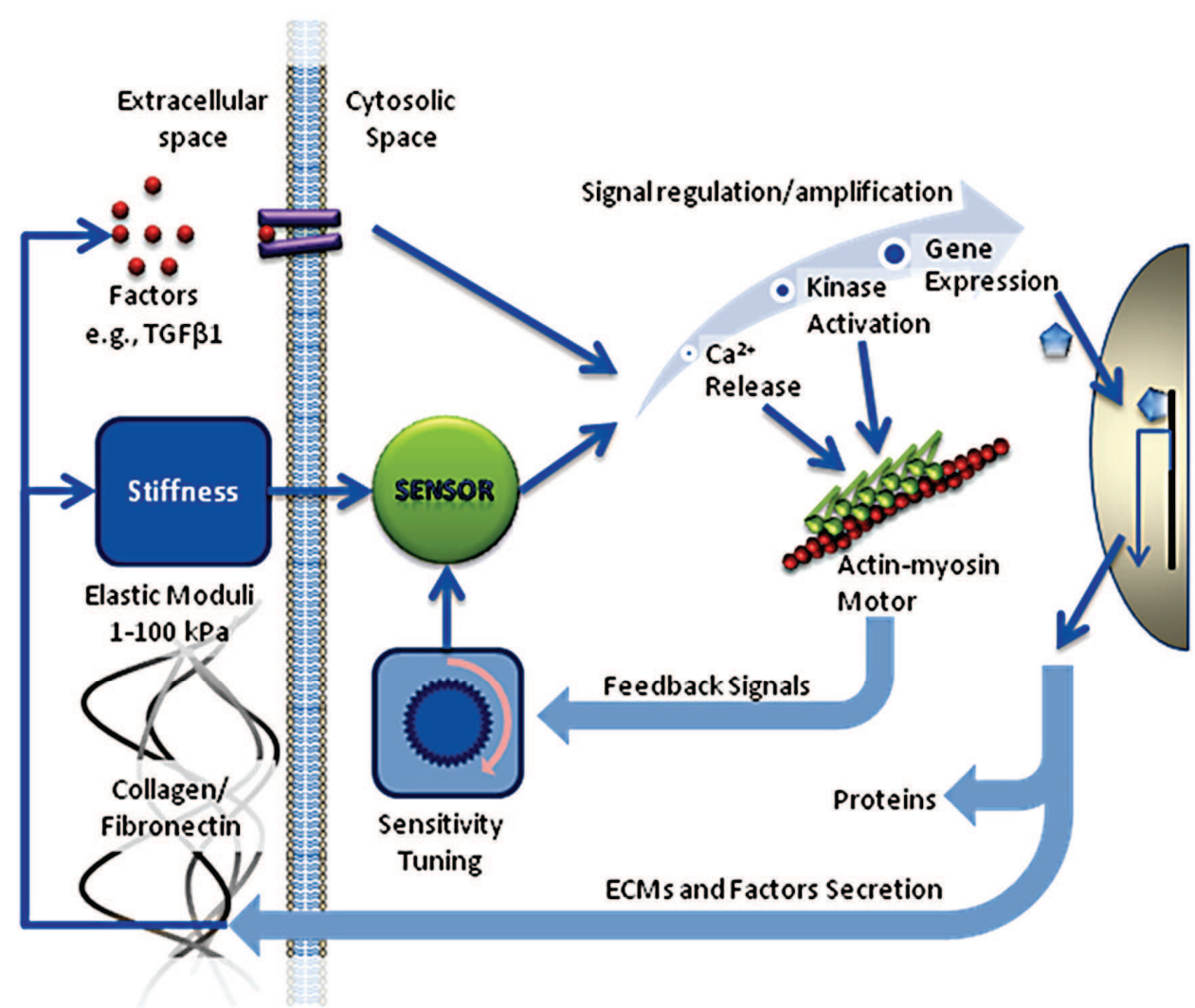

Fig. 1. Regulation of Mechanical Tissue Homeostasis Establishment

As demonstrated elegantly for p130Cas [25], a simple analogy of the biological sensory mechanism is represented as a mechanical strain gauge that measures applied forces by detecting small deformations of proteins. Depending on an elastic strength of the gauge (i.e., protein), its sensitivity can be varied. In general the sensitivity becomes higher by reducing the elasticity of the gauge material since it can deform more with a same applied force. We and others [18] assume that the molecular strain gauges are coupled to the actin-myosin forming stress fibers whose elasticity or stiffness is modulated by activity of myosin. The receptor activation initiated by binding of various soluble factors triggers and modulates myosin activity. Therefore, the sensitivity of the mechanical sensor can be modulated. Eventually the mechanical properties of cell and extracellular matrix reach a steady state to find homeostasis. However, its specific mechanism by which sensors can modulate their sensitivity and determination of the homeostasis are yet to be elucidated. Nevertheless, the concept of the establishment of homeostasis between the cells and ECM comprising "tissue" should be considered carefully while designing and developing the functional tissues in vitro. The mechanical properties of engineered tissues have to match with donor tissues, especially for those carrying critical mechanical functions including the cardiovascular system. As described, varying stiffness of the extracellular environment takes 
part in dictating stem cell fates [34]. Rapid high throughput tissue phenotyping can be used to test various soluble and mechanical stimuli to yield an optimal tissue with desired functions.

\section{Cardiac tissue phenotyping and their potential to assay-automation}

The assay system by which developers can evaluate the functional improvement that results from optimizing the tissue fabrication and culture conditions will have to accurately observe the physiological functions of cardiac tissues. The contractility of cardiac tissues is the most fundamental functional readout that can indicate the functional improvement by varying the tissue fabrication conditions. The regulatory system of cardiac contractility should also be reconstituted in the engineered tissues, which will be evaluated through rapid prototyping. As listed in Table 1, EHT-based contractility assessment is ideal for assessing cardiac functions in high-throughput, as compared to the other techniques that have traditionally been used to assess the function of myocytes, myocardium, and isolated hearts. Each method has its own advantages and disadvantages. The assay results using isolated adult cells and papillary muscles will continue to serve as references for the expected muscle cell and tissue contractility and its regulation. However, they can not report the tissue functions. Cardiac contractility assays using isolated Langendorff preparation has been gradually replaced by hemodynamic measurements using pressure-volume conductance catheters [35] as well as echo cardiography. Nevertheless, the whole heart functional assay can be used to assess functional improvement that results from the tissue transplantation.

\begin{tabular}{lcccc}
\hline & $\begin{array}{c}\text { Engineered } \\
\text { Heart Tissues }\end{array}$ & $\begin{array}{c}\text { Isolated Adult } \\
\text { Cells }\end{array}$ & $\begin{array}{c}\text { Papillary } \\
\text { Muscles }\end{array}$ & $\begin{array}{c}\text { Langendorff } \\
\text { Preps }\end{array}$ \\
\hline Sample viability period & Weeks to months & $\sim 6 \mathrm{hrs}$ & $\sim 6-8 \mathrm{hrs}$ & $\sim 8 \mathrm{hrs}$ \\
\hline $\begin{array}{l}\text { Contractility } \\
\text { measurements with } \\
\text { preload. }\end{array}$ & Yes (various) & No ${ }^{*}$ & Yes (various) & $\begin{array}{c}\text { Yes (various, } \\
\text { PV loop) }\end{array}$ \\
$\begin{array}{l}\text { Optical assessment of } \\
\text { live cells }\end{array}$ & Yes (easy) & Yes (easy) & Yes (not easy) & No (generally) \\
\hline $\begin{array}{l}\text { High throughput } \\
\text { testing }\end{array}$ & Yes & Yes & No & No \\
\hline $\begin{array}{l}\text { Sample damage by } \\
\text { isolation }\end{array}$ & No & Yes & Yes & Yes \\
\hline $\begin{array}{l}\text { Comments } \\
\text { Reconstituted } \\
\text { system }\end{array}$ & $\begin{array}{c}\text { High data } \\
\text { variance }\end{array}$ & & $\begin{array}{c}\text { Widely used } \\
\text { standards. }\end{array}$ \\
\hline
\end{tabular}

* Isolated adult cells can be stretched by carbon fiber techniques [2]. High throughput measurements and range of stretching are limited.

Table 1. Comparison of methods for measuring cardiac contractility in vitro

Once the EHTs start contracting, they maintain contractility for at least 2-3 weeks. Assessment of acute and chronic changes in contractility and cell physiology can thus be 
monitored for long periods using EHTs. Even though EHTs are artificially reconstituted organoids, their histological structure and functional properties are similar to those in native myocardium $[5,36]$. Each EHT is fabricated by pouring a gel solution containing predefined concentrations of cells, matrix proteins, and growth factors into a precisely machined well [5]. Since 1993, similar engineered tissues have been used as a model system to study signal transduction pathways that regulate contractility of fibroblasts [37], smooth muscle cells, skeletal muscle cells [8]. We were the first to introduce the use of tissue models to determine effective drug doses [38] and have recently extended the application of this technology to include phenotypic screening [39]. We demonstrated the phenotypic difference in tissue mechanics between wildtype cells and mutant cells with truncated $a_{1}$ integrin [40]. We also extended the applications of engineered tissue models by creating cardiac tissue constructs [41]. Recently, we introduced the concept of growing mini-tissues in 96-well plates for high-throughput drug screening [42]. Initially engineered heart tissues were fabricated using a tissue fabrication mold that cast hydrogel into a ring [5]. To miniaturize the tissues, we developed tissue fabrication wells similar to those used in 96-well format. The center-to-center distance of 96-well plates is 9 millimeters. We developed $8 \mathrm{~mm} \times 8 \mathrm{~mm}$ square wells to fabricate the engineered tissues. We demonstrated the automation of contractile measurements of EHTs to improve the productivity of the proposed studies. The generation of EHTs using pluripotent stem cells will open up the new pathways to develop engineered tissues using human cells. However, there are several issues that need to be solved before benefitting highly promising technology.

\section{Multi cell types require functional cardiac patches using iPSCs}

Human iPSCs, which are generated by genetic reprogramming of somatic cells to an infinitely self-renewing pluripotent state [43, 44], offer an excellent source for robust generation of large numbers of human cardiac myocytes (CMs), endothelial cells (ECs) and fibroblasts (FBs), which are all needed for producing a vital EHT in vitro [45]. Protocols to generate somatic cells from hPSCs typically attempt to recapitulate cardiac development in an accelerated manner by temporal application of differentiation cues[45]. For example directed differentiation protocols that achieve high yield and purity of CMs from human pluripotent stem cells apply basic FGF, TGF $\beta$ superfamily ligands, VEGF, and Wnt agonists and antagonists at precise differentiation stages [46, 47]. Recently CMs generated from human embryonic stem cells (hESCs) have been injected into rodent cardiac muscle; these CMs engrafted, survived, and resulted in functional improvement in myocardial infarction models [47];[48]. HESC-derived CMs and ECs assembled into spontaneously contracting patches and, when implanted on a rodent pericardium, survived and anastomosed [45]. This study clearly indicates that multiple cell types are necessary in generating functional cardiac patches.

Because of the requirement of multi cell types to fabricate functional cardiac patches, the high throughput rapid prototyping system can contribute to identifying the optimal combination of cell types to fabricate the best cardiac patches. Not only varying the number of CMs, ECs, and FBs to initiate the fabrication, the response to each cell type to various hormones, growth factors, and mechanical environment will have to be screened again to find the best combinations. Therefore, a rapid prototyping system that can screen various 
test conditions will be critically needed to establish functional tissues with desired phenotypes.

\section{Summary}

Systematically optimizing a tissue-fabrication protocol will require an iterative process of changing the parameters of fabrication and tissue culture conditions incrementally after measuring the resulting functional improvement. To test a large number of these parameters to the best outcome, many tissues have to be fabricated and their function has to be evaluated in high-throughput. To achieve this prototyping cost-effectively, the samples have to be miniaturized. Most importantly, establishing the tissue homeostasis in the engineered tissue has to be achieved either before implantation or by taking account how tissue homeostasis will be established with the acceptor's existing tissue. In vivo tissue organ phenotyping with transplanted tissues will be as important as availability of rapid prototyping of engineered tissues.

\section{Acknowledgements}

We thank Mr. David Glaubke for his contribution to the careful reading of manuscript and editorial comments.

\section{Sources of funding}

This research was supported in part by NIH GM087784 grant

\section{References}

[1] Roberts, M.S., Improving the Supply of Donor Organs. JAMA: The Journal of the American Medical Association, 2010. 304(23): p. 2643-2644.

[2] Yasuda, S.-I., et al., A novel method to study contraction characteristics of a single cardiac myocyte using carbon fibers. Am J Physiol Heart Circ Physiol, 2001. 281(3): p. H1442-1446.

[3] Zimmermann, W.-H., et al., Heart muscle engineering: An update on cardiac muscle replacement therapy. Cardiovascular Research, 2006. 71(3): p. 419-429.

[4] Zimmermann, W.-H. and R. Cesnjevar, Cardiac Tissue Engineering: Implications for Pediatric Heart Surgery. Pediatric Cardiology, 2009. 30(5): p. 716-723.

[5] Asnes, C.F., et al., Reconstitution of the Frank-Starling mechanism in engineered heart tissues. Biophys J, 2006. 91(5): p. 1800-10.

[6] Wakatsuki, T., K.W. Lieder, and A. Annac, Engineered Tissue Models: Innovative Tools for Early-Stage, Information-Dense, High-Throughput Screening for Drug Discovery. American Biotechnology Laboratory, 2006(Nov/Dec).

[7] Nelson, C.M., J.L. Inman, and M.J. Bissell, Three-dimensional lithographically defined organotypic tissue arrays for quantitative analysis of morphogenesis and neoplastic progression. Nat. Protocols, 2008. 3(4): p. 674-678.

[8] Vandenburgh, H., High-Content Drug Screening with Engineered Musculoskeletal Tissues. Tissue Engineering Part B: Reviews, 2010. 16(1): p. 55-64. 
[9] Marquez, J.P., et al., High-Throughput Measurements of Hydrogel Tissue Construct Mechanics. Tissue Eng Part C Methods, 2009.

[10] Morelock, M.M., et al., Statistics of Assay Validation in High Throughput Cell Imaging of Nuclear Factor $\mathrm{\kappa B}$ Nuclear Translocation. ASSAY and Drug Development Technologies, 2005. 3(5): p. 483-499.

[11] Hartwell, L.H., et al., From molecular to modular cell biology. Nature.

[12] Cukierman, E., et al., Taking cell-matrix adhesions to the third dimension. Science, 2001. 294(5547): p. 1708-12.

[13] Engler, A.J., et al., Extracellular matrix elasticity directs stem cell differentiation. J Musculoskelet Neuronal Interact, 2007. 7(4): p. 335.

[14] Pedersen, J.A. and M.A. Swartz, Mechanobiology in the third dimension. Ann Biomed Eng, 2005. 33(11): p. 1469-90.

[15] Pankov, R., et al., A Rac switch regulates random versus directionally persistent cell migration. J Cell Biol, 2005. 170(5): p. 793-802.

[16] Green, J.A. and K.M. Yamada, Three-dimensional microenvironments modulate fibroblast signaling responses. Adv Drug Deliv Rev, 2007. 59(13): p. 1293-8.

[17] Torsoni, A.S., et al., RhoA/ROCK signaling is critical to FAK activation by cyclic stretch in cardiac myocytes. American Journal of Physiology - Heart and Circulatory Physiology, 2005. 289(4): p. H1488-H1496.

[18] Sarasa-Renedo, A., V. Tunç-Civelek, and M. Chiquet, Role of RhoA/ROCK-dependent actin contractility in the induction of tenascin-C by cyclic tensile strain. Experimental Cell Research, 2006. 312(8): p. 1361-1370.

[19] Ueyama, T., et al., Activated RhoA stimulates c-fos gene expression in myocardial cells. Circ Res, 1997. 81(5): p. 672-8.

[20] Aikawa, R., et al., Rho family small G proteins play critical roles in mechanical stressinduced hypertrophic responses in cardiac myocytes. Circ Res, 1999. 84(4): p. 45866.

[21] Hoshijima, M., et al., The low molecular weight GTPase Rho regulates myofibril formation and organization in neonatal rat ventricular myocytes. Involvement of Rho kinase. J Biol Chem, 1998. 273(13): p. 7725-30.

[22] Yanazume, T., et al., Rho/ROCK pathway contributes to the activation of extracellular signal-regulated kinase/GATA-4 during myocardial cell hypertrophy. J Biol Chem, 2002. 277(10): p. 8618-25.

[23] Tomasek, J.J., et al., Myofibroblasts and mechano-regulation of connective tissue remodelling. Nat Rev Mol Cell Biol, 2002. 3(5): p. 349-363.

[24] Slemp, A.E. and R.E. Kirschner, Keloids and scars: a review of keloids and scars, their pathogenesis, risk factors, and management. Current Opinion in Pediatrics, 2006. 18(4): p. 396-402 10.1097/01.mop.0000236389.41462.ef.

[25] Sawada, Y., et al., Force Sensing by Mechanical Extension of the Src Family Kinase Substrate p130Cas. Cell, 2006. 127(5): p. 1015-1026.

[26] Small, E.M., et al., Myocardin-Related Transcription Factor-A Controls Myofibroblast Activation and Fibrosis in Response to Myocardial Infarction. Circ Res, 2010. 107(2): p. 294-304.

[27] Shi, Y. and J. Massagué, Mechanisms of TGF-[beta] Signaling from Cell Membrane to the Nucleus. Cell, 2003. 113(6): p. 685-700. 
[28] Du, J., et al., TRPM7-Mediated Ca2+ Signals Confer Fibrogenesis in Human Atrial Fibrillation. Circ Res, 2010. 106(5): p. 992-1003.

[29] Sturm, O.E., et al., The Mammalian MAPK/ERK Pathway Exhibits Properties of a Negative Feedback Amplifier. Sci. Signal., 2010. 3(153): p. ra90-.

[30] Wakatsuki, T. and E.L. Elson, Reciprocal interactions between cells and extracellular matrix during remodeling of tissue constructs. Biophysical Chemistry, 2003. 100(1-3): p. 593-605.

[31] Bendig, G., et al., Integrin-linked kinase, a novel component of the cardiac mechanical stretch sensor, controls contractility in the zebrafish heart. Genes $\mathcal{E}$ Development, 2006. 20(17): p. 2361-2372.

[32] KJÆR, M., Role of Extracellular Matrix in Adaptation of Tendon and Skeletal Muscle to Mechanical Loading. Physiological Reviews, 2004. 84(2): p. 649-698.

[33] Maier, S., et al., Tenascin-C induction by cyclic strain requires integrin-linked kinase. Biochimica et Biophysica Acta (BBA) - Molecular Cell Research, 2008. 1783(6): p. 11501162.

[34] Russo, R., et al., Lack of increased expression of cell surface markers for circulating fibrocyte progenitors in limited scleroderma. Clin Rheumatol, 2007. 26(7): p. 1136-41.

[35] Pacher, P., et al., Measurement of cardiac function using pressure-volume conductance catheter technique in mice and rats. Nat. Protocols, 2008. 3(9): p. 1422-1434.

[36] Eschenhagen, T. and W.H. Zimmermann, Engineering myocardial tissue. Circ Res, 2005. 97(12): p. 1220-31.

[37] Kolodney, M.S. and E.L. Elson, Correlation of myosin light chain phosphorylation with isometric contraction of fibroblasts. Journal of Biological Chemistry, 1993. 268(32): p. 23850-5.

[38] Wakatsuki, T., et al., Effects of cytochalasin D and latrunculin B on mechanical properties of cells. J Cell Sci, 2001. 114(Pt 5): p. 1025-36.

[39] Wakatsuki, T., J.A. Fee, and E.L. Elson, Phenotypic screening for pharmaceuticals using tissue constructs. Curr Pharm Biotechnol, 2004. 5(2): p. 181-9.

[40] Zutter, M.M., et al., Collagen receptor control of epithelial morphogenesis and cell cycle progression. Am J Pathol, 1999. 155(3): p. 927-40.

[41] Eschenhagen, T., et al., Three-dimensional reconstitution of embryonic cardiomyocytes in a collagen matrix: a new heart muscle model system. Faseb J, 1997. 11(8): p. 683-94.

[42] Flanagan, N., Tissue Models Boost Drug Discovery Efforts; Eliminating Toxic and Ineffective Compounds at an Early Stage. Genetic Engineering News, 2005. 25(20): p. 1

[43] Takahashi, K., et al., Induction of pluripotent stem cells from adult human fibroblasts by defined factors. Cell, 2007. 131(5): p. 861-72.

[44] $\mathrm{Yu}$, J., et al., Human induced pluripotent stem cells free of vector and transgene sequences. Science, 2009. 324(5928): p. 797-801.

[45] Stevens, K.R., et al., Physiological function and transplantation of scaffold-free and vascularized human cardiac muscle tissue. Proceedings of the National Academy of Sciences, 2009. 106(39): p. 16568-16573.

[46] Yang, P.T., et al., Wnt signaling requires retromer-dependent recycling of MIG14/Wntless in Wnt-producing cells. Dev Cell, 2008. 14(1): p. 140-7. 
[47] Laflamme, M.A., et al., Cardiomyocytes derived from human embryonic stem cells in pro-survival factors enhance function of infarcted rat hearts. Nat Biotechnol, 2007. 25(9): p. 1015-24.

[48] Caspi, O., et al., Tissue engineering of vascularized cardiac muscle from human embryonic stem cells. Circ Res, 2007. 100(2): p. 263-72. 


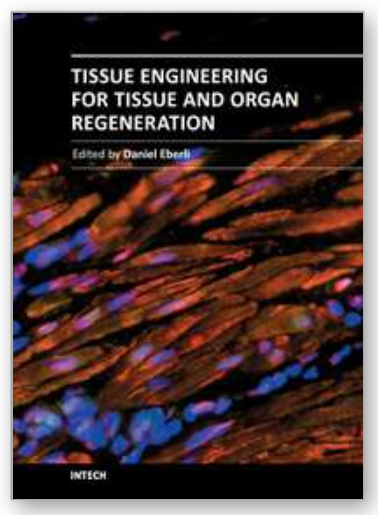

\author{
Tissue Engineering for Tissue and Organ Regeneration \\ Edited by Prof. Daniel Eberli
}

ISBN 978-953-307-688-1

Hard cover, 454 pages

Publisher InTech

Published online 17, August, 2011

Published in print edition August, 2011

Tissue Engineering may offer new treatment alternatives for organ replacement or repair deteriorated organs. Among the clinical applications of Tissue Engineering are the production of artificial skin for burn patients, tissue engineered trachea, cartilage for knee-replacement procedures, urinary bladder replacement, urethra substitutes and cellular therapies for the treatment of urinary incontinence. The Tissue Engineering approach has major advantages over traditional organ transplantation and circumvents the problem of organ shortage. Tissues reconstructed from readily available biopsy material induce only minimal or no immunogenicity when reimplanted in the patient. This book is aimed at anyone interested in the application of Tissue Engineering in different organ systems. It offers insights into a wide variety of strategies applying the principles of Tissue Engineering to tissue and organ regeneration.

\title{
How to reference
}

In order to correctly reference this scholarly work, feel free to copy and paste the following:

Tetsuro Wakatsuki (2011). Rapid Prototyping of Engineered Heart Tissues through Miniaturization and Phenotype-Automation, Tissue Engineering for Tissue and Organ Regeneration, Prof. Daniel Eberli (Ed.), ISBN: 978-953-307-688-1, InTech, Available from: http://www.intechopen.com/books/tissue-engineering-fortissue-and-organ-regeneration/rapid-prototyping-of-engineered-heart-tissues-through-miniaturization-andphenotype-automation

\section{INTECH}

open science | open minds

\author{
InTech Europe \\ University Campus STeP Ri \\ Slavka Krautzeka 83/A \\ 51000 Rijeka, Croatia \\ Phone: +385 (51) 770447 \\ Fax: +385 (51) 686166 \\ www.intechopen.com
}

\author{
InTech China \\ Unit 405, Office Block, Hotel Equatorial Shanghai \\ No.65, Yan An Road (West), Shanghai, 200040, China \\ 中国上海市延安西路65号上海国际贵都大饭店办公楼405单元 \\ Phone: +86-21-62489820 \\ Fax: +86-21-62489821
}


(C) 2011 The Author(s). Licensee IntechOpen. This chapter is distributed under the terms of the Creative Commons Attribution-NonCommercialShareAlike-3.0 License, which permits use, distribution and reproduction for non-commercial purposes, provided the original is properly cited and derivative works building on this content are distributed under the same license. 